\title{
Current Practices for Screening and Management of Financial Distress at NCCN Member Institutions
}

\author{
Nandita Khera, MD, MPH${ }^{1}$; Jessica Sugalski, MPPA²; Diana Krause, MHA²; Richard Butterfield III, MS'; Nan Zhang, MS ${ }^{1}$;
} F. Marc Stewart, MD³; Robert W. Carlson, MD²; Joan M. Griffin, PhD'; S. Yousuf Zafar, MD; and Stephanie J. Lee, MD ${ }^{3}$

\section{ABSTRACT}

Background: Financial distress from medical treatment is an increasing concern. Healthcare organizations may have different levels of organizational commitment, existing programs, and expected outcomes of screening and management of patient financial distress. Patients and Methods: In November 2018, representatives from 17 (63\%) of the 27 existing NCCN Member Institutions completed an online survey. The survey focused on screening and management practices for patient financial distress, perceived barriers in implementation, and leadership attitudes about such practices. Due to the lack of a validated questionnaire in this area, survey questions were generated after a comprehensive literature search and discussions among the study team, including NCCN Best Practices Committee representatives. Results: Responses showed that $76 \%$ of centers routinely screened for financial distress, mostly with social worker assessment $(94 \%)$, and that $56 \%$ screened patients multiple times. All centers offered programs to help with drug costs, meal or gas vouchers, and payment plans. Charity care was provided by $100 \%$ of the large centers ( $\geq 10,000$ unique annual patients) but none of the small centers that responded $(<10,000$ unique annual patients; $P=.008$ ). Metrics to evaluate the impact of financial advocacy services included number of patients assisted, bad debt/charity write-offs, or patient satisfaction surveys. The effectiveness of institutional practices for screening and management of financial distress was reported as poor/very poor by $6 \%$ of respondents. Inadequate staffing and resources, limited budget, and lack of reimbursement were potential barriers in the provision of these services. A total of $94 \%$ agreed with the need for better integration of financial advocacy into oncology practice. Conclusions: Three-fourths of NCCN Member Institutions reported screening and management programs for financial distress, although the actual practices and range of services vary. Information from this study can help centers benchmark their performance relative to similar programs and identify best practices in this area.

J Natl Compr Canc Netw 2020;18(7):825-831 doi: $10.6004 /$ jnccn.2020.7538

${ }^{1}$ Mayo Clinic Alix School of Medicine, Phoenix, Arizona; ${ }^{2}$ National Comprehensive Cancer Network, Plymouth Meeting, Pennsylvania; ${ }^{3}$ Fred Hutchinson Cancer Research Center, University of Washington Children's Hospital, Seattle, Washington; ${ }^{4}$ Mayo Clinic, Rochester, Minnesota; and ${ }^{5}$ Duke University Medical Center, Durham, North Carolina.

\section{Background}

Financial distress from medical treatment is a multidimensional construct that includes material hardship, psychological burden, and adverse coping behaviors as a result of costs of care borne by patients. ${ }^{1}$ It is an increasing concern for patients with cancer, families, and healthcare providers and can impact $12 \%$ to $80 \%$ of patients with cancer. ${ }^{2-8}$ It can lead to treatment nonadherence, lifestyle changes for patients (such as cutting back on leisure activities and reduced spending on utilities or food), borrowing money from friends or relatives, or mortgaging or selling homes or other assets, and may result in an increase in patient mortality. $2,4,6,9-12$ The urgent need for integrating the assessment and optimal management of patient financial burden into the routine delivery of cancer care has been highlighted recently. ${ }^{13}$

To date, most studies on financial distress have been descriptive studies of patient experiences and have identified components of financial burden and their prevalence. ${ }^{1,14-17}$ The increasing costs of cancer care and its impact on patients have certainly made healthcare providers more aware of their role in reducing financial toxicity through improved communication about costs and an emphasis on patient navigation and financial counseling. It is important to realize that the goal of these services is to help patients obtain fiscally responsible care rather than stigmatizing or leading to rationing of care so that screening for financial distress is not perceived as a threat. Several recent studies have examined the attitudes and practices of providers such as physicians and social workers regarding communication about costs. ${ }^{18-21}$ These studies have highlighted challenges in the delivery of financial advocacy services, such as limited financial resources, shortage of well-trained staff, and ethical struggles due to conflict between patient welfare, affordability, and social justice. In addition, systemic barriers, such as a lack of price 
transparency and difficulty navigating the complex and fragmented healthcare system, are prevalent. Both providers and patients are usually not aware of the overall and patient-specific costs until patients receive their bill for services.

Unlike the mandate for overall distress screening and management by the American College of Surgeons' Commission on Cancer, there are no standard recommendations for financial distress screening and management yet. Hence, understanding the variation in organizational commitment and existing programs regarding assessment and management of financial distress is needed to identify barriers to comprehensive but affordable cancer care for all who need it, and potential areas for quality improvement. Identifying and validating appropriate and acceptable metrics can also help individual practices evaluate the progress of their programs once strategies to mitigate financial distress are applied. Finally, having this information can assist institutions in benchmarking their own organization's performance relative to other cancer programs and to identify best-practice models in this area.

In this study, we sought to determine the current state of financial distress management practices, perceived barriers, and leadership attitudes regarding implementation of these practices at NCCN Member Institutions. We also examined the prevalence and impact of incremental financial burden associated with clinical trial participation at these centers. We hypothesized a wide variation in screening and management practices for financial burden based on center characteristics such as center size/volume and leadership attitudes regarding perceived susceptibility, severity, benefits, and barriers (components of the Health Belief Model) to address this problem. ${ }^{22}$

\section{Patients and Methods}

\section{Survey Development and Administration}

Based on a review of relevant literature and discussion with study team members, including representatives from the NCCN Best Practices Committee, a web survey with 23 items was developed to assess the specific domains of interest (supplemental eAppendix 1, available with this article at JNCCN.org). ${ }^{23-25}$ The NCCN Best Practices Committee is composed of senior physician and administrative leaders from NCCN Member Institutions and works toward improving the effectiveness and efficiency of cancer center operations. The committee conducts surveys regarding processes, programs, and policies at NCCN Member Institutions. The Institutional Review Board at Mayo Clinic determined this study to be exempt.
The Donabedian framework has been used to evaluate the quality of healthcare services using 3 main categories: structure, processes, and outcomes. ${ }^{26}$ Our survey aimed to evaluate these 3 aspects of practice around financial distress screening and management at NCCN Member Institutions. Questions included how, when, and which patients were screened for financial distress. The number and type of financial assistance services and personnel providing these services were assessed. Additional questions inquired about cancer center practice structure, barriers to integration of financial distress screening and management in routine clinical practice, and financial burden related to clinical trials. Attitudes of leadership and administration regarding the effectiveness of their institution's screening and management practices were assessed, as was their agreement about the integration of financial advocacy services into oncology practice and its use as a quality metric.

Feedback regarding the content and face validity of the survey, the ability to interpret essential information, and the time required to complete the survey was collected by piloting the instrument with a committee member from one of the NCCN Member Institutions. The survey was sent via email in November 2018 to representatives of the 27 existing NCCN Member Institutions, with an email reminder sent 10 days later to nonrespondents. No incentives were offered. There were not many missing data in the responses. The only missing data were from one center that did not provide financial distress screening, and therefore all of the questions related to financial stress screening for that center were not applicable.

Analysis

Descriptive statistics were used to analyze cancer center characteristics. Centers were classified based on the number of unique patients seen per year as large $(\geq 10,000)$ or small $(<10,000)$. Primary outcomes were financial distress screening and assistance services in routine clinical practice. These outcomes were compared between large and small centers using the Wilcoxon rank sum or Fisher exact test as applicable. The Wilcoxon rank sum test is a nonparametric test in which the only assumption is that the observations from both groups (small and large centers) are independent of each other. The Fisher exact test was used because of the small sample size and because the expected cell size was $<5$. Therefore, we concluded that the data met the assumptions of the statistical tests. Likert scale responses for questions about the effectiveness of screening and management of financial distress were converted to a binary scale with possible responses of "excellent/good" and "neutral/poor/extremely poor" and 
compared between large and small centers. Perceived barriers, the impact of financial distress screening and management services, and leadership attitudes around the importance of integrating these services were also reported in a descriptive fashion.

\section{Results}

Completed surveys were received from 17 of the 27 existing NCCN Member Institutions (response rate, $63 \%$ ). Respondents included administrative directors or leaders of patient financial services $(n=12)$, nursing $(n=2)$, or social work/case management $(n=3)$, and $82 \%$ indicated that $\geq 10,000$ unique patients were seen annually at their center. The median number of inpatient beds dedicated to cancer care at these centers was 133 (range, 20-650). The payer mix in terms of insurance sources was variable: privately insured populations ranged from $35 \%$ to $55 \%$, publicly insured populations ranged from $40 \%$ to $60 \%$, and uninsured populations ranged from $0 \%$ to $10 \%$ at the centers (Table 1). Smaller centers reported higher median publicly insured populations than larger centers (58\% vs $50 \% ; P=.03$ ).

\section{Financial Distress Screening}

Among responding centers, $76 \%(\mathrm{n}=13)$ screened patients routinely for financial distress, $18 \%(n=3)$ screened occasionally, and $6 \%(\mathrm{n}=1)$ did not screen at

\section{Table 1. Payer Mix at NCCN Member Institutions}

\begin{tabular}{|cccccc|} 
Center & $\begin{array}{c}\text { Private } \\
\text { Insurance }\end{array}$ & $\begin{array}{c}\text { Medicare } \pm \\
\text { Secondary } \\
\text { Insurance }\end{array}$ & Medicaid & Uninsured & Other \\
\hline 1 & $55 \%$ & $35 \%$ & $5 \%$ & $5 \%$ & \\
\hline 2 & $50 \%$ & $41 \%$ & $8 \%$ & $1 \%$ & \\
\hline 3 & $50 \%$ & $37 \%$ & $11 \%$ & $2 \%$ & $0 \%$ \\
\hline 4 & $48 \%$ & $48 \%$ & $3 \%$ & $1 \%$ & \\
\hline 5 & $48 \%$ & $41 \%$ & $11 \%$ & $0 \%$ & $0 \%$ \\
\hline 6 & $46 \%$ & $45 \%$ & $6 \%$ & & $3 \%$ \\
\hline 7 & $45 \%$ & $33 \%$ & $20 \%$ & $2 \%$ & \\
\hline 8 & $45 \%$ & $20 \%$ & $25 \%$ & $10 \%$ & \\
\hline 9 & $43 \%$ & $41 \%$ & $13 \%$ & $1 \%$ & $2 \%$ \\
\hline 10 & $42 \%$ & $35 \%$ & $6 \%$ & $8 \%$ & $9 \%$ \\
\hline 11 & $42 \%$ & $48 \%$ & $6 \%$ & $2 \%$ & $2 \%$ \\
\hline 12 & $42 \%$ & $38 \%$ & $20 \%$ & & \\
\hline 13 & $40 \%$ & $40 \%$ & $20 \%$ & & \\
\hline 14 & $40 \%$ & $45 \%$ & $12 \%$ & $2 \%$ & $1 \%$ \\
\hline 15 & $40 \%$ & $40 \%$ & $15 \%$ & $5 \%$ & \\
\hline 16 & $38 \%$ & $37 \%$ & $7 \%$ & & $18 \%$ \\
\hline 17 & $35 \%$ & $40 \%$ & $20 \%$ & $5 \%$ & \\
\hline & & & & & \\
\hline
\end{tabular}

all. The representative from center 15 , a small center that responded "no" to the screening question, noted that they "are in the process of exploring how to provide financial navigation/toxicity evaluation and then mitigation. We have spoken with VIVOR about their product and are interested in exploring a pilot. However, we have not had the right full-time equivalent and roles in place." Table 2 shows the differences in screening practices between the large and the small centers. Social workers or financial counselors were often responsible for screening in $>90 \%$ of the institutions; $50 \%$ of the centers used the NCCN Distress Thermometer or other distress tools to assess for financial distress and 19\% used a dedicated financial distress questionnaire. In response to an openended question regarding financial screening and assistance services, one of the large center representatives wrote, "We are able to provide a number of resources, but we often don't know about need until there is a crisis. We are moving toward a universal screening tool to be administrated that focuses specifically on financial distress" (center 4).

Half of the centers screened patients multiple times during the cancer diagnosis and treatment continuum; $75 \%$ screened all patients for financial distress and $25 \%$ screened targeted groups of patients (eg, elderly patients, those with multiple comorbidities, and those with certain types of insurance) or patients receiving certain types of treatment. One of the centers screened all uninsured patients, insured patients with an annual patient responsibility $>\$ 10,000$, patients with limited benefits, and patients using their out-of-network benefits to identify those in need earlier in order to connect them with assistance measures up front. Meanwhile, another large center representative reported, "We utilize lay patient navigators that interact with all new patients and/or their patient panel. Additionally, our multidisciplinary patient-intake RNs perform an abbreviated screening resulting in referral to navigators or our patient assistance center" (center 17). No significant differences in screening practices were found among centers based on the payer mix (ie, insurance sources; data not shown). A total of $63 \%$ of the centers rated the overall effectiveness of their institution's practices for screening financial distress as good or excellent. The ratings were not statistically different between large and small centers $(78 \%$ vs $33 \%$, respectively; $P=.19$ ) and centers that performed routine screening versus occasional screening $(69 \%$ vs $33 \%$, respectively; $P=.21$ ).

\section{Financial Distress Management}

Help with drug costs, meal or gas vouchers, and payment plans was offered by $100 \%$ of centers that screened patients with cancer for financial distress. Charity care for 


\begin{tabular}{|c|c|c|c|}
\hline & $\begin{array}{l}\text { Small Centers } \\
\text { n (\%) }\end{array}$ & $\begin{array}{l}\text { Large Centers } \\
\quad \text { n (\%) }\end{array}$ & $P$ Value \\
\hline Centers, $\mathrm{n}$ & 2 & 14 & \\
\hline \multicolumn{4}{|l|}{ Financial distress screening method used } \\
\hline NCCN Distress Thermometer or other distress tool & $2(100)$ & $6(43)$ & $.47^{c}$ \\
\hline Financial questionnaire & $0(0)$ & $3(21)$ & $1.00^{c}$ \\
\hline Social worker & $1(50)$ & $14(100)$ & $.13^{\mathrm{c}}$ \\
\hline Other & $1(50)$ & $8(57)$ & $1.00^{c}$ \\
\hline \multicolumn{4}{|l|}{ Type of financial assistance services offered } \\
\hline Pharmaceutical drug replacement/copayment assistance programs & $2(100)$ & $14(100)$ & NA \\
\hline Assistance with transportation costs, meal vouchers, and gas cards & $2(100)$ & $14(100)$ & NA \\
\hline Charity care for help with medical costs & $0(0)$ & $14(100)$ & $.008^{c}$ \\
\hline Discussion with a representative & $2(100)$ & $11(79)$ & $1.00^{c}$ \\
\hline Development of payment plans & $2(100)$ & $14(100)$ & NA \\
\hline Assistance with claims and denials & $1(50)$ & $12(86)$ & $.35^{\circ}$ \\
\hline Referral of patients to third party & $2(100)$ & $8(57)$ & $.50^{c}$ \\
\hline Counseling/support for nonmedical financial challenges & $2(100)$ & $10(71)$ & $1.00^{c}$ \\
\hline \multirow[t]{2}{*}{ Other } & $0(0)$ & $1(7)$ & $1.00^{c}$ \\
\hline & Median (Range) & Median (Range) & \\
\hline $\begin{array}{l}\text { Personnel to help with assessment and/or management of financial } \\
\text { distress }\end{array}$ & $17(6-28)$ & $69(15-351)$ & $.05^{\mathrm{d}}$ \\
\hline Social worker & $5(1-9)$ & $19(3-64)$ & $.09^{\mathrm{d}}$ \\
\hline Case manager & $2(1-2)$ & $6(0-111)$ & $.57^{d}$ \\
\hline Financial navigators & $1(0-1)$ & $4(0-11)$ & $.37^{d}$ \\
\hline Patient accounting services representative & $3(1-4)$ & $8(0-125)$ & $.27^{\mathrm{d}}$ \\
\hline Pharmacy representatives & $3(1-4)$ & $6(1-40)$ & $.11^{d}$ \\
\hline RN coordinators/oncology nurses & $5(1-8)$ & $12(0-240)$ & $.81^{d}$ \\
\hline ACS navigator & $1(0-1)$ & $0(0-0)$ & $.01^{\mathrm{d}}$ \\
\hline
\end{tabular}

Abbreviations: ACS, American Cancer Society; NA, not available.

a $<10,000$ unique annual patients.

$b \geq 10,000$ unique annual patients.

cFisher exact test.

dWilcoxon rank sum test.

medical costs was provided by $100 \%$ of the large centers compared with $0 \%$ of the small centers that responded to the question $(P=.008)$. Availability of other assistance services was not significantly different between small and large centers (Table 2). The median number of personnel helping with assessment and/or management of financial distress for patients undergoing cancer treatment was 59 (range, 6-351), and $75 \%$ of respondents rated the overall effectiveness of their institution's practices for managing financial distress as good or excellent.

Seventy-six percent of centers evaluated the impact of the financial screening and management services they provided. In these centers, metrics used to evaluate this impact included the number of patients who were assisted with these issues (85\% of centers), bad debt and charity write-offs $(85 \%)$, dollars used to provide support (69\%), and patient satisfaction surveys (54\%).

\section{Financial Burden Associated With Clinical Trials}

A total of $47 \%$ of the centers had $>500$ active trials. More than half of the centers (53\%) reported having patients refuse clinical trials because of financial concerns mostly related to out-of-pocket costs for medications and travel. Most centers $(82 \%)$ provided financial counseling to help potential trial participants understand the costs covered by the trial versus the patient/insurance responsibility, and offered support such as financial counseling and parking vouchers. When asked about 
support provided to clinical trial participants, such as financial counseling, the representative at center 5 (a large center) mentioned, "The demand to review financial counseling services specific to clinical trials is on the rise. The hospital would need to be staffed appropriately for this to be a success."

\section{Integration of Financial Advocacy Services/ Leadership Attitudes}

Inadequate staffing and real-time resources (69\%) were cited as the most common barrier to the integration of financial advocacy services with routine clinical care (Table 3 ). At least 3 centers reported that patients were not interested or comfortable in availing themselves of these services, and 1 center reported that identifying patients with limited benefits was a major challenge. Among respondents, $94 \%$ agreed on the need for stronger integration of financial advocacy services into oncology practice, and $82 \%$ felt that the success of these services should be a quality metric. In response to the question about a plan for a staffing increase for these services, a large center's respondent (center 8) said, "We will continue to monitor the volume of patients applying for financial assistance to confirm if additional staff is warranted."

\section{Discussion}

Identifying and addressing potential issues related to the economics of a cancer diagnosis is an area of high need. An incentive to control the costs of care overall would be to decrease the magnitude of financial burden for patients. Various stakeholders, such as providers, institutions, patients, payers, pharmaceutical and device manufacturers, and others, need to come together to seek solutions to decrease the costs of care. Until those solutions are found and implemented, efforts need to focus on recognizing, preventing, and managing financial hardship in patients with cancer with the goal of providing comprehensive but affordable cancer care.

In this study, we found that even though most NCCN Member Institutions provide screening and management programs for financial distress, there is wide variation in the practices and range of services offered. Gaps in terms of how, when, and who is screened for financial distress were identified; for example, half of the programs screened only once during the cancer continuum, and one-fourth of the programs screened only certain types of patients. Even though $100 \%$ of the programs provided basic financial assistance, such as help with drug costs, meal or gas vouchers, and payment plans, other services such as formal preauthorization programs or assistance with claims and denials were not offered uniformly. Center size may influence some aspects, such as number

\begin{tabular}{|lr|}
\hline $\begin{array}{l}\text { Table 3. Barriers to Integration of Financial } \\
\text { Advocacy Services (N= 16) }\end{array}$ \\
\hline Barriers & $\mathbf{n}(\%)$ \\
\hline Limited institutional budget & $8(50)$ \\
\hline Poor or no reimbursement for such services & $8(50)$ \\
\hline Clinical time constraints & $8(50)$ \\
\hline Inadequate staffing and real-time resources & $11(69)$ \\
\hline Lack of effective risk mitigation strategies $^{\text {Patients not interested }}$ & $3(19)$ \\
\hline Others $^{\mathrm{a}}$ & $2(13)$ \\
\hline
\end{tabular}

aDifficulty identifying patients with limited benefits, lack of full-time employees to support fully comprehensive financial navigation structure, and staff and/or patients uncomfortable talking about financial situations and concerns.

of certain personnel and availability of charity care, but it did not explain all of the variation in practice. We also did not find any significant impact of payer mix on screening and management practices.

The 2014 Trends in Cancer Programs Survey by the Association of Community Cancer Centers (ACCC) focused on financial advocacy as a growing field and reported on somewhat similar information as our study. ${ }^{25}$ That survey, which was completed by 110 cancer programs (mostly hospital-based cancer centers but also some university-affiliated programs and private practices), indicated that $90 \%$ of the programs offered financial assistance services provided by "financial specialists" or "reimbursement specialists" in addition to nurse navigators and social workers, compared with $100 \%$ of the programs in our survey. In the ACCC survey, $14 \%$ of the programs used third-party commercial financial assistance specialists that charged for services, compared with $63 \%$ of the programs in our survey. The differences in our results may be due to variations in sample size and type of institutions surveyed (academic vs community cancer centers) or the overall progress that has occurred in the field in the past 6 years; the exact cause is difficult to determine because of a lack of details about the structure and volume of respondents in the 2014 survey.

We assessed the incremental financial burden of clinical trials at the NCCN Member Institutions. Participants in clinical trials have been considered a vulnerable population from a financial burden standpoint because of high additional out-of-pocket expenses for travel, meals, lodging, and other incidental costs associated with participating in trials, more so than the general cancer population..$^{27}$ Almost half of the centers in our study reported that their patients refused clinical trial participation as a result of financial considerations, but acknowledged that refusals were 
not tracked uniformly. Only approximately one-third of the centers provided support, such as financial counseling or parking vouchers, specifically for all clinical trial participants regardless of the trial or sponsor. It is very likely that the financial barriers to clinical trial accrual may be worse for community practices with limited research resources and a more diverse patient pool.

The increasing financial burden of cancer treatment is becoming a challenge for patients and their families as well as healthcare providers. For patients and families, increased cost-sharing along with a prolonged trajectory of illness is adversely affecting access to quality outcomes of cancer care. ${ }^{1}$ For providers, the challenge lies in being able to provide affordable care in an equitable fashion and avoiding noncompliance with treatment recommendations among their patients due to concern about costs. For institutions, there is an increased likelihood of financial loss due to unpaid bills and suboptimal reimbursements from payers, which can adversely impact the quality of care delivered. Despite recognizing these issues, institutions can face challenges in providing financial advocacy services at times. Our study highlights some of these challenges, including inadequate staffing and real-time resources, limited institutional budget, lack of reimbursement, and clinical time constraints. Despite these barriers, most cancer center leadership in our survey agreed that a stronger integration of such services is necessary for screening and management of financial distress with routine oncology care.

How can we facilitate the integration of screening and management of financial distress with routine clinical care? We can start by raising awareness among all relevant stakeholders about these issues to help improve communication and to remove the stigma that patients may feel when having these conversations. ${ }^{28,29}$ Interventions to help improve financial health at the population level, such as employee assistance programs, credit counseling, and financial planning, may supplement the support provided at the institutional level.

Use of educational tools to improve health-related financial literacy and facilitate problem-focused coping around financial issues, financial navigation to decrease stress and anxiety due to the cost of care, and improved social support may help address some challenges at the patient level but will require institutional commitment. ${ }^{30}$ It is possible that supportive programs at cancer centers that help reduce existing or potential financial burdens for patients can increase the financial viability of the institution providing medical care, although that should not be the primary motive for such programs. Having a clear set of metrics to assess the success of such programs can help in understanding the impact at both the institutional and the patient level. Including financial toxicity questions on patient satisfaction surveys may provide feedback and pressure on institutions to increase attention to this type of treatment complication. Finally, support for increased resource allocation and health policy changes can help address the barriers of limited resources and staffing for this issue at organizational levels.

Our study has limitations. First, not all NCCN Member Institutions responded to the survey, and therefore the number of centers studied was low and precluded inferential statistical comparisons. Our response rate of $63 \%$ was somewhat lower than the $70 \%$ to $80 \%$ response rates in other studies conducted in a similar fashion but with different stakeholders. Second, the responses corresponded to the views of the institutional representative who completed the survey. These individuals held different leadership positions at their respective cancer centers (such as Director of Patient Financial Services, Director of Operations, Associate Vice President of Medical Operations, and Director of Case Management) but were felt to be the most knowledgeable about their center practices in this area. In addition, we did not collect extensive demographic data for the patients seen at the cancer centers. In terms of the assistance services provided, we did not include explicit questions about help with employment-based issues to address financial toxicity. Finally, we included only NCCN Member Institutions, thereby limiting the generalizability of these findings. The low response rate, the use of only NCCN Member Institutions that may be accessible only to certain types of patients, and self-reported information raise the possibility of bias. For example, it is possible that some larger centers that usually have a higher frequency of screening and assistance services may have been more motivated to reply to the survey. Future efforts to address these limitations are to widen the sample population to a mix of academic and community cancer centers and practices and to survey more than one stakeholder from each center.

\section{Conclusions}

Notwithstanding the limitations, this study provides valuable information about current financial distress screening and management practices at the NCCN Member Institutions leveraging the network provided by the NCCN Best Practices Committee. The information provided by our study advances the field of financial advocacy and identifies the barriers and best practices in the area. Our results provide the background to conduct research on novel integration models and quality improvement measures regarding financial distress screening and management at the institutional level. 
Submitted August 13, 2019; accepted for publication January 15, 2020.

Author contributions: Study and survey design: Khera, Sugalski, Griffin, Zafar, Lee. Literature search and drafting of manuscript: Khera. Survey administration and results compilation: Sugalski, Krause. Statistical analyses: Butterfield, Zhang. Interpretation of findings, critical review, and final approval of manuscript: All authors.
Disclosures: The authors have disclosed that they have not received any financial consideration from any person or organization to support the preparation, analysis, results, or discussion of this article. Ms. Sugalski, Ms. Krause, and Dr. Carlson are employed by NCCN.

Correspondence: Nandita Khera, MD, MPH, Mayo Clinic Alix School of Medicine 5777 East Mayo Boulevard, Phoenix, AZ 85054. Email: khera.nandita@mayo.edu

\section{References}

1. Altice CK, Banegas MP, Tucker-Seeley RD, et al. Financial hardships experienced by cancer survivors: a systematic review. J Natl Cancer Inst 2016;109:djw205.

2. Zafar SY, Peppercorn JM, Schrag D, et al. The financial toxicity of cancer treatment: a pilot study assessing out-of-pocket expenses and the insured cancer patient's experience. Oncologist 2013;18:381-390.

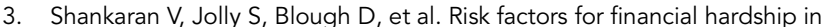
patients receiving adjuvant chemotherapy for colon cancer: a populationbased exploratory analysis. J Clin Oncol 2012;30:1608-1614.

4. Khera N, Chang YH, Hashmi S, et al. Financial burden in recipients of allogeneic hematopoietic cell transplantation. Biol Blood Marrow Transplant 2014;20:1375-1381.

5. Jagsi R, Pottow JAE, Griffith KA, et al. Long-term financial burden of breast cancer: experiences of a diverse cohort of survivors identified through population-based registries. J Clin Oncol 2014;32:1269-1276.

6. Kent EE, Forsythe LP, Yabroff KR, et al. Are survivors who report cancerrelated financial problems more likely to forgo or delay medical care? Cancer 2013;119:3710-3717

7. Kodama $Y$, Morozumi R, Matsumura $T$, et al. Increased financial burden among patients with chronic myelogenous leukaemia receiving imatinib in Japan: a retrospective survey. BMC Cancer 2012;12:152.

8. Huntington SF, Weiss BM, Vogl DT, et al. Financial toxicity in insured patients with multiple myeloma: a cross-sectional pilot study. Lancet Haematol 2015;2:e408-416.

9. Abel GA, Albelda R, Khera N, et al. Financial hardship and patientreported outcomes after hematopoietic cell transplantation. Biol Blood Marrow Transplant 2016;22:1504-1510.

10. Chino F, Peppercorn J, Taylor DH Jr, et al. Self-reported financial burden and satisfaction with care among patients with cancer. Oncologist 2014; 19:414-420.

11. Fenn KM, Evans SB, McCorkle R, et al. Impact of financial burden of cancer on survivors' quality of life. J Oncol Pract 2014;10:332-338.

12. Kelley RK, Venook AP. Nonadherence to imatinib during an economic downturn. N Engl J Med 2010;363:596-598.

13. Khera N, Holland JC, Griffin JM. Setting the stage for universal financial distress screening in routine cancer care. Cancer 2017;123:4092-4096.

14. de Souza JA, Yap BJ, Wroblewski K, et al. Measuring financial toxicity as a clinically relevant patient-reported outcome: the validation of the COmprehensive Score for financial Toxicity (COST). Cancer 2017;123: 476-484.

15. Dusetzina SB, Basch E, Keating NL. For uninsured cancer patients, outpatient charges can be costly, putting treatments out of reach. Health Aff (Millwood) 2015;34:584-591.
16. Ramsey SD, Bansal A, Fedorenko CR, et al. Financial insolvency as a risk factor for early mortality among patients with cancer. J Clin Oncol 2016 34:980-986.

17. Yabroff KR, Dowling EC, Guy GP Jr, et al. Financial hardship associated with cancer in the United States: findings from a population-based sample of adult cancer survivors. J Clin Oncol 2016;34:259-267.

18. Smith SK, Nicolla J, Zafar SY. Bridging the gap between financial distress and available resources for patients with cancer: a qualitative study. J Oncol Pract 2014;10:e368-372.

19. Schrag D, Hanger M. Medical oncologists' views on communicating with patients about chemotherapy costs: a pilot survey. J Clin Oncol 2007;25: 233-237.

20. Ubel PA, Zhang CJ, Hesson A, et al. Study of physician and patient communication identifies missed opportunities to help reduce patients' out-of-pocket spending. Health Aff (Millwood) 2016;35: 654-661.

21. Altomare I, Irwin B, Zafar SY, et al. ReCAP: physician experience and attitudes toward addressing the cost of cancer care. J Oncol Pract 2016; 12:247-248

22. Rosenstock IM, Strecher VJ, Becker MH. Social learning theory and the Health Belief Model. Health Educ Q 1988;15:175-183.

23. Coluzzi PH, Grant M, Doroshow JH, et al. Survey of the provision of supportive care services at National Cancer Institute-designated cancer centers. J Clin Oncol 1995;13:756-764.

24. Jacobsen PB, Ransom S. Implementation of NCCN Distress Management Guidelines by member institutions. J Natl Compr Canc Netw 2007;5: 99-103.

25. Association of Community Cancer Centers. 2014 Trends Survey. Accessed February 19, 2020. Available at: https://www.accc-cancer.org/home/ learn/publications/Trends/2014

26. Donabedian A. Evaluating the quality of medical care. Milbank Mem Fund Q 1966:44:166-206.

27. Nipp RD, Powell E, Chabner B, et al. Recognizing the financial burden of cancer patients in clinical trials. Oncologist 2015;20:572-575.

28. Aakhus E, Rosenstein A, Joffee S, Bradbury AR. Implementing cost transparency in oncology: a qualitative study of barriers, facilitators, and patient preferences [abstract]. J Clin Oncol 2017;35(Suppl): Abstract 6597.

29. Bullock AJ, Hofstatter EW, Yushak ML, et al. Understanding patients' attitudes toward communication about the cost of cancer care. J Oncol Pract 2012;8:e50-58.

30. Shankaran $V$, Leahy $T$, Steelquist $J$, et al. Pilot feasibility study of an oncology financial navigation program. J Oncol Pract 2018;14:e122-129. 
Supplemental online content for:

\section{Current Practices for Screening and Management of Financial Distress at NCCN Member Institutions}

Nandita Khera, MD, MPH; Jessica Sugalski, MPPA; Diana Krause, MHA; Richard Butterfield III, MS;

Nan Zhang, MS; F. Marc Stewart, MD; Robert W. Carlson, MD; Joan M. Griffin, PhD;

S. Yousuf Zafar, MD; and Stephanie J. Lee, MD

J Natl Compr Canc Netw 2020;18(7):825-831

eAppendix 1: NCCN Best Practices Management of Financial Distress Survey 


\section{eAppendix 1.}

\section{NCCN Best Practices Management of Financial Distress Survey}

\section{FOR REFERENCE ONLY. PLEASE COMPLETE VIA SURVEYMONKEY.}

The NCCN Best Practice Committee is conducting a survey regarding the barriers around screening and management of financial distress at your cancer center. Your participation is greatly appreciated.

1. Contact Information:

Name:

Title:

Member Institution:

Email:

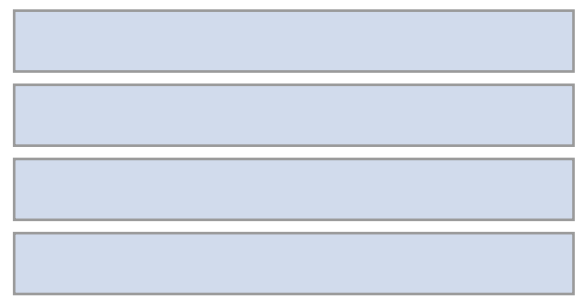

2. How many unique patients are seen at your cancer center annually?

$<<, 000$

$5,000-9,999$

$>10,000$

3.What is the number of inpatient beds dedicated to cancer care at your center?

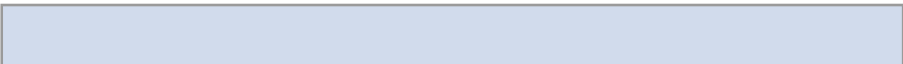

4. What is the approximate case mix seen at your center in terms of insurance sources in the last year? (Totals must add to $100 \%$ )

\begin{tabular}{ll|} 
Private \\
Medicare with or without \\
secondary \\
Medicaid
\end{tabular}

Other (please specify): 


\section{NCCN Best Practices Management of Financial Distress Survey (cont.)}

5. Does your center screen patients with cancer for financial distress?

Yes, routinely

Yes, occasionally

$\bigcirc$ No

6. How is financial distress screened for at your center? (Please check all that apply)

$\square$ As part of overall distress using NCCN Distress Thermometer or other distress tool

$\square$ Independently using a financial questionnaire

$\square$ Social worker assessment

$\square$ Other

Other (please describe):

7. When are patients screened for financial distress at your center?

Prior to being seen at the center

At the time of initial clinic visit

At the time of starting treatment

Multiple times during the cancer diagnosis and treatment continuum

At the time of change in sociodemographic status such as insurance changes

Other

If other, please describe:

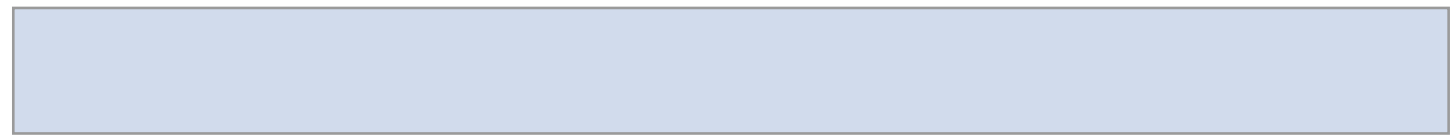

8. Which patients are screened for financial distress? (Please check all that apply)

All patients (universal screening)

$\square$ Certain types of patients (eg, elderly, those with multiple comorbidities, those with certain types of insurance)

$\square$ Certain types of cancer

$\square$ Certain types of treatment 


\section{NCCN Best Practices Management of Financial Distress Survey (cont.)}

9. How would you rate the overall effectiveness of your institutional practice for screening financial distress?

Extremely poor

Poor

Neutral

Good

Excellent

10. What type of financial assistance services does your center offer? (Please check all that apply)

$\square$ Help accessing pharmaceutical drug replacement/copayment assistance programs

$\square$ Assistance with transportation costs, meal vouchers, and gas cards

$\square$ Charity care for help with medical costs

$\square$ Discussion with a representative about cost-of-care estimates through a formal preauthorization and cost-estimation program

$\square$ Develop payment plans with patients

$\square$ Help with insurance and billing questions

$\square$ Assist with claims and denials

$\square$ Refer patients to third-party organizations for help with financial education/counseling/case management services

$\square$ Counseling/support for nonmedical financial challenges exacerbated by cancer diagnosis and treatment

$\square$ Other

Other (please specify):

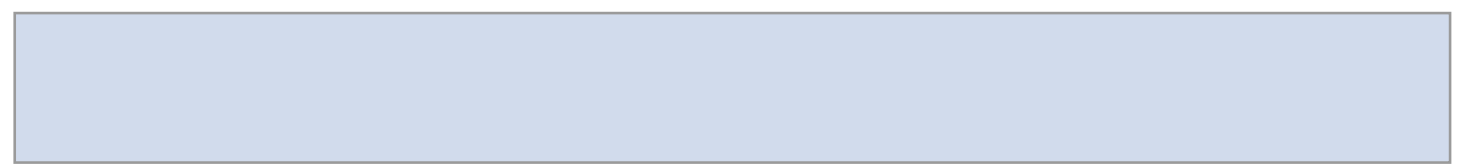


NCCN Best Practices Management of Financial Distress Survey (cont.)

11. At your center, please estimate the number of personnel that would usually help with assessment and/or management of financial distress for patients undergoing cancer treatment.

Social workers

Case managers

Financial navigators

Patient accounting

services/billing

department

representatives

Pharmacy

representatives

RN coordinators/

oncology nurses

ACS navigator

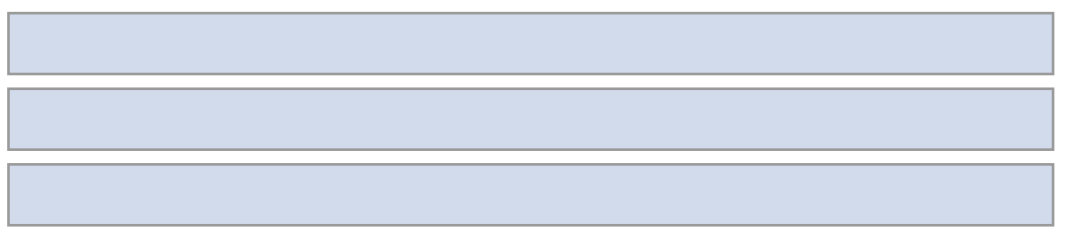

Other

12. How would you rate the overall effectiveness of your institutional practice for management of financial distress?
Extremely poor
Poor
Neutral
Good
Excellent

13. Does your center evaluate outcomes/impact of financial advocacy services provided to the patients?

Yes

No 


\section{NCCN Best Practices Management of Financial Distress Survey (cont.)}

14. How is the impact of these services evaluated?

Number of patients assisted by staff performing these services

$\square$ Bad debt and charity write-offs

$\square$ Dollar value of copay cards/charity care to help with gas bills, food coupons provided annually

$\square$ Patient satisfaction surveys

$\square$ Other (please specify):

15. How many active clinical trials does your center have at present?
$<<200$
200-499
$\geq 500$

Comments:

16. Have you had patients refuse clinical trial participation due to financial concerns?

Yes; $<50 \%$ of the time

Yes; $>50 \%$ of the time

No

Do not know

Comments:

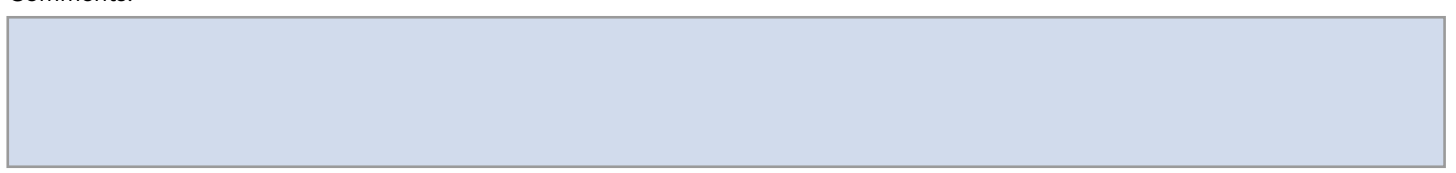

17. Does your center provide financial analyses to help potential trial participants understand the costs covered by the trial versus patient/insurance responsibility?

Yes

No 
NCCN Best Practices Management of Financial Distress Survey (cont.)

18. Does your center ever provide support specifically for clinical trial participants, such as financial counseling, parking vouchers, etc.?

Yes, for all trials

Yes, for certain trials

No

Comments:

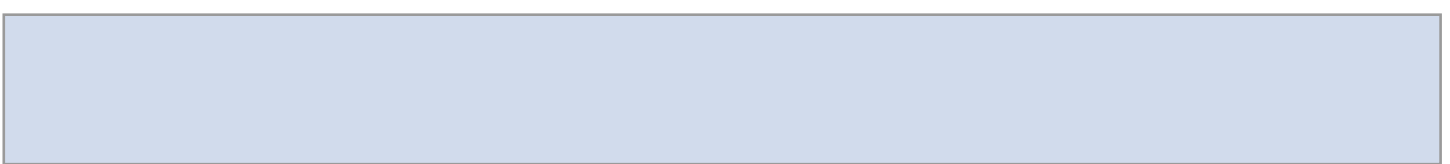

19. Irrespective of whether assessment and management of financial distress is offered at your institution, what in your opinion are some of the potential barriers in integration of financial advocacy services at your institution? (Please check all that apply)

$\square$ Limited institutional budget

Poor or no reimbursement for such services

$\square$ Clinical time constraints

Inadequate staffing and real time resources

$\square$

Lack of effective risk mitigation strategies

Patients not interested

Other

Other (please specify):

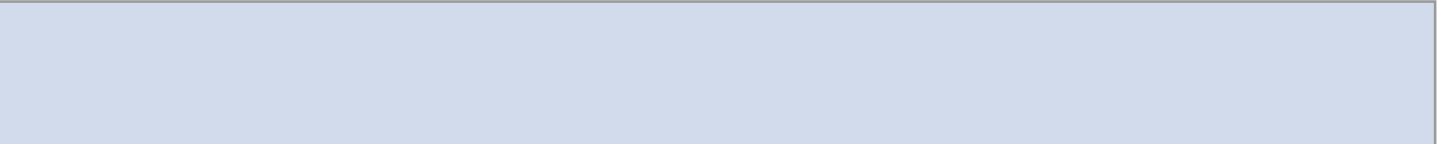

20. Should a stronger integration of financial advocacy services into oncology practice be required at cancer centers?

Strongly agree

Agree

Neutral

Disagree

Strongly disagree 
NCCN Best Practices Management of Financial Distress Survey (cont.)

21. Should the success of financial advocacy services be a quality metric?

Strongly agree

Agree

Neutral

Disagree

Strongly disagree

22. Will your institution be increasing the number of personnel in the area of financial advocacy services over the next 5 years?

Definitely no

No

Unsure

$\bigcirc$ Yes

Definitely yes

Comments:

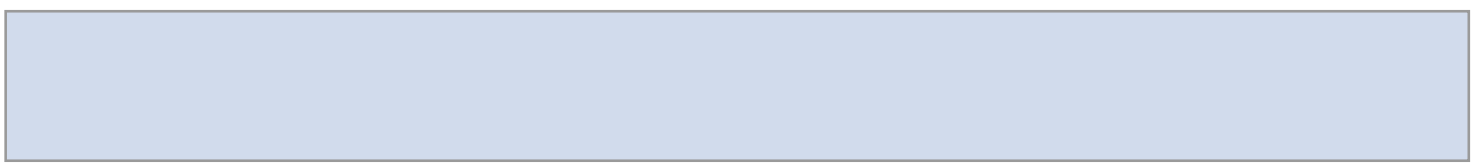

23. Please feel free to provide any other comments you may have about institutional screening and management of financial distress.

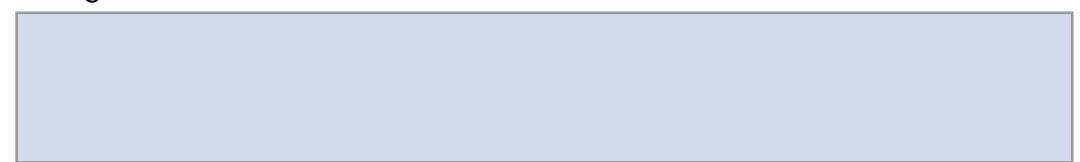

